\title{
The "Metaphorical Collage" as a Research Tool in the Field of Education
}

\author{
Gila Russo-Zimet
}

Department of Education, Levinsky College of Education, Israel

Copyright $(2016$ by authors, all rights reserved. Authors agree that this article remains permanently open access under the terms of the Creative Commons Attribution License 4.0 International License

\begin{abstract}
The aim of this paper is to propose a research tool in the field of education - the "metaphorical collage". This tool facilitates the understanding of concepts and processes in education through the analysis of metaphors in collage works that include pictorial images and verbal images. We believe the "metaphorical collage" to be an important research tool that enables both researcher and research participant to understand children's worldview in regards to concepts in the field of education. The collage permits the use of expressive language in order to describe the question under investigation. The researcher has the ability to interpret the meaning of the events in which people are involved, and he is also capable of evaluating their educational significance. It is the researcher who is equipped with the requisite ability, sensitivity, and experience for conducting research by means of the "metaphorical collage". With the help of the collage, the educational situation is grasped, and its meaning is interpreted.
\end{abstract}

Keywords Research Tool, Metaphor, Educational Tool, Qualitative Research

\section{Introduction}

The aim of this paper is to propose a research tool in the field of education - the "metaphorical collage". This tool facilitates the understanding of concepts and processes in education through the analysis of metaphors in collage works that include pictorial images and verbal images. The tool fits a case study that is anchored in a qualitative research worldview. Case study is a recommended method to examine a specific special phenomenon, profoundly understand what directs a group of people to take action or a way to collect a great number of findings in order to understand a certain human phenomenon [34]. Case study fits a single case study and collective case study (multiple case study) [39] and can be considered a stage towards more detailed understandings and generalizations.

Case study uses many research tools to gather data: observations, archival materials, notes from interviews, tapes, documents, journals, program documentations and more [33]. This tool joins the rest of the tools designed to collect data and emphasizes a unique data analysis. Data analysis is usually made either by contents analysis or form analysis (or both), discourse analysis, holistic analysis and other designated tools developed in recent years. The presented research tool combines contents and form analysis of written text, discourse analysis and analysis of visual elements presented in the collage. All done with focus on the metaphor as a leading connecting aspect of all the components that shed light and deepen understanding of the case. Its uniqueness is portrayed in its name "metaphorical (metaphor) collage (collection)".

There are a number of tools used to analyze verbal metaphors that expose understandings or beliefs - interviews, personal stories, questionnaires, and observations. These tools analyze the discourse of the participants $[4 ; 16]$. However, the "metaphorical collage" is different from the tools mentioned above. It is an expressive tool that reflects reality, relays messages, and reveals meanings and employs metaphor in visual representation as a means of communication. As Maurice Merleau Ponty [22] states: "There is no seeing without thinking, but it is not enough to think in order to see: seeing is conditioned thinking; what happens in the body is an 'opportunity' for the birth of seeing; it 'awakens' it to thinking" (p. 56).

The process of developing the tool started a few years ago. It began as an exercise in a class of third year early childhood education students in a teachers college. During this class before learning an important chapter about integrating the child with special needs in the regular classroom I wanted to expose the students' perceptions regarding integrating children with special needs in regular classrooms. I chose the collage as a tool to describe their perceptions. I was surprised by the amount of information and the differences in perceptions. At this time I learned about the cognitive metaphor as a way to uncover understandings. That lesson was the beginning and the motive to develop the tool. During the course of my work I used metaphorical collage as a mean to expose perceptions in different areas in my work as a pedagogic instructor and in didactics classes. In order to validate the tool I turned to 
two psychologists colleagues of mine and asked them to become associates in the process of validation. In a joint research we examined students' perceptions of teaching, learning and evaluation. A description of the tool and the research results were published in Hebrew and became the beginning of the road to continuing to improve the research tool $[37,38]$.

Over the years I have used this tool extensively in my work at instructing graduate final projects, undergraduate projects and instructing other lecturers to use the tool. Using the tool often has provided me with many other insights regarding the tool and made it come together as a liable reliable and valid research tool and how it is used. The tool presented here is a development of the first tool that was developed in the past. (Out of respect to the first participants in developing the tool, I will use plural first person).

The tool we developed, presented in this article, is based on a theory of visual literacy, principally on the relation to the visual realm as a communicative language $[3 ; 2 ;[9] ; ; 9$; 10]. Rowland [26] claims that visual language is not a taste or a style. In his view, it is composed of visual means that express a spiritual climate of time and place. Visual language contains signs in the form of combinations of components such as dots, lines, spots, surfaces, colors, textures and images - in other words, signs of visual grammar [3; 9]. It also contains signs and combinations that are culture, time, and space dependent.

In addition to visual literacy, we have chosen to adopt the theory of "cognitive metaphor" as an image that creates identical features for two elements or two properties that are being relocated from one semantic field to another. Starting from the 1980s, Lakoff and Johnson [19, 20;17] developed a different direction for understanding the metaphor as conceptual and cognitive. Following their lead, other researchers $[5 ; 6 ; 8 ; 11,12 ; 21 ; 25]$ also related to the metaphor as a cardinal and basic mechanism in thinking. In this sense, the metaphor is a sub-field in symbolic cognition, a field that includes building concepts, solving problems, drawing conclusions, explaining systems, and so on. These researchers claimed that expressions in our language are not coincidental, but rather they reflect overt and hidden layers of conceptual understanding and, for that reason, they are referred to as "conceptual metaphors". Accordingly, the nature of the metaphorical process is thinking about a given thing in terms of another thing. The "topic" or "tenor" under discussion is the "target domain", and the "source domain" serves as a vehicle for the "target domain". Since the metaphor is a process of transposition from a source domain to a target domain, the source domain is a content-rich conceptual domain from which properties and relations are borrowed and transposed to the target domain. Examples of content-rich concepts are the human body, physical terms, objects, food, and so on. Each of them reflects a different understanding of the target domain, thereby responding to the speakers' expressive needs.

Below, we will demonstrate how the conceptual metaphors discussed by these authors come to the fore in the analysis of a picture and in its conceptual image, employing caricaturist Zeev's caricature of a fable, "A Bar Mitzvah Boy and a Gold Watch", from Levin Kipnis' book, Fables (1974).

In his poem, Kipnis talks about a boy who received a gold watch from his uncle for his bar mitzvah. He guards the watch jealously and does not take it off for a second. When the uncle sees that his nephew does not part with his watch, he tells him: "I gave you a watch, dear boy, so that you could appreciate every moment, and you're wasting your time looking after the watch. [...] Time is more valuable than gold" (p. 7). The poem clearly illustrates to the reader that its main message is the importance of time. The text is accompanied by the pictorial image drawn by Zeev.

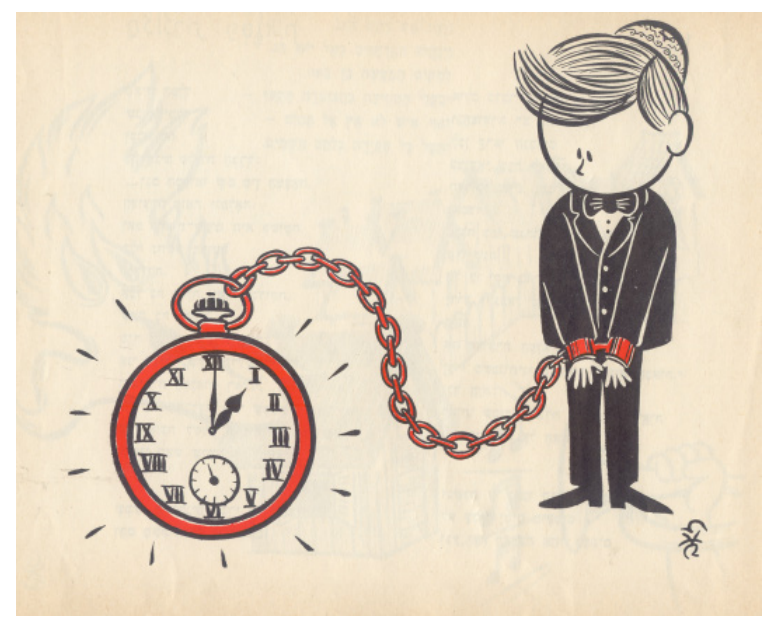

Figure 1. A caricature by Zeev

Through the illustration (a boy chained to a watch) and its conceptual metaphorical analysis, the caricature conjures up an additional meaning to the one that emerges from the words of the poem. We will therefore analyze the conceptual metaphors in the illustration. Two source domains can be identified in it: the chain and the watch; and between them and the boy, a clear link exists: it shackles him, it is unpleasant, and it generates discomfort. In other words, the target domain is the boy, and the source domains are the watch and the chain. The meaning of the target domain in the metaphorical tool is elicited by conceptual mapping from the two source domains: the first source domain is the chain; we see a concrete object which is often used by a police officer to fetter the prisoner. Thus, in its broad sense, it reflects a negative experience. The second source domain is the watch, by means of which we know the time. Thus, in its broad sense, it represents time. The mapping that derives from the joining of the two source domains and their transposition to the target domain creates a new meaning: the burden of time is like the burden of the chain on the prisoner's hands. In other words, through the conceptual analysis, the illustration - or in this case, the caricature - affords an additional understanding of the verbal text.

This understanding is what guided us during the conceptual analysis of pictorial images as a tool for exposing the understandings that arose from the verbal text. We chose to realize the visual expression by creating a collage, which allows numerous pictorial types and methods to be employed simultaneously. The research participants could draw either 
a caricature or a regular picture, add one or more written words, paste ready-made images from newspapers, magazines, and so on - as they pleased.

It is assumed that a collage that uses a visual text that includes verbal and pictorial references alike will expand the researcher's field of vision vis-à-vis his understanding of the topic under investigation. Furthermore, the analysis of a text by analyzing the metaphor as a communication system will also enable a broader understanding of the research participant's attitudes.

I will specify two examples of using collage as a research tool in two published articles. One in which the participants are adult students and the other in which the participants are children in kindergarten.

A study that examined how early-childhood educators that pursue their graduate degrees perceive the concept of happiness, as conveyed in visual representations. The research tool was the "metaphoric collage". The research population included 32 students from various locations in Israel. The findings revealed that the concept of happiness is perceived as love, spirituality and emotions. In their collages, approximately half of the participants represented happiness as a list of separate and fragmented components such as children, health etc., while others attempted to find connections and relations in order to achieve a more profound view of happiness. Although the majority of the participants experienced happiness as intellectual and intangible, they did not perceive academic studies and learning processes as a component of happiness [28].

The "metaphoric collage" was also used as a research tool in the study "young children's perception of the concept of noise as conveyed in visual representations" .The research was published in an online Journal in Hebrew. An analysis of the findings revealed a strikingly profound understanding of the concept of noise in early childhood. The children related to three aspects in their perception of the concept: (1) external sources of noise (vehicles, machines); (2) causes of noise - they stressed human activity as a cause of noise (playing an instrument, stamping, banging, walking); (3) properties of noise - they indicated volume (high, low), and movement as properties of noise [27].

\section{The Tool - Metaphorical Collage}

In order to present the research tool, we have opted to relate to the following six aspects: (a) data collected; (b) data analyzed; these two parts include an example to collecting and analyzing the data; (c) validity; (d) credibility; (e) advantages; (f) limitations.

Following is a description of each aspect:

(a) Data Collected

Two factors are stressed in the data collection process: the establishment of preliminary ties with the participant, and the reinforcement of the interpersonal ties between researcher and participant by means of three stages:

(1) Presentation of the materials for preparing the collage and giving instruction to the participants.

(2) Explanation of the product by the participants.

(3) Dialogue between the participant and the researcher.

\section{(1) Presentation of the materials for preparing the collage and giving the instruction to the participants:}

The participants were allowed to use all possible materials, including their own written texts, cutting or pasting backgrounds, stepping out of the margins, and so on. The researcher did not interfere in the participants' work. If one of the participants wanted to address the researcher, the latter approached him without disturbing the others. The participants were given maximum freedom, and were reminded of the guidance provided and the permission to use additional materials'.

They were provided with a collection of photos and pictures from newspapers, monthly journals, magazines, and weeklies; equipment for joining and linking (scissors, staplers, paste); colors and pencils (colored felt-tipped pens preferably two packages of 12 for 10 participants, as well as a pencil, a pen, and a thick black felt-tipped pen for each participant); backgrounds (preferably a Bristol board, $35 \mathrm{X}$ $25 \mathrm{~cm}$, with no limitations of color or quantity). Instructions: "In front of you are various materials. Try to use them in any way you choose to express the idea/concept/process. You have up to 30 minutes." (If the research participant requests an extension, it must be granted.) "Please do not talk to the other participants while you are working."

The participants include 25 students in early childhood education in the last year of their studies during didactic lesson at Levinsky College of Education. All the participants were female aged 22-30 years old residing in the center part of Israel.

They were allowed to use all possible materials, including their own written texts, cutting or pasting backgrounds, stepping out of the margins, and so on.

The researcher did not interfere in the participants' work. If one of the participants wanted to address the researcher, the latter approached him without disturbing the others. The participants were given maximum freedom, and were reminded of the guidance provided and the permission to use additional materials.

(2) Explanation of the product by the participant: Once the collage was completed, the participant was requested:

To give numbers to the images as he saw fit during the collage work.

To explain his work in writing in accordance with the following directions: "Please provide a detailed written description of the collage." (If the participant was a young child, the researcher would write the explanation down or record it).

While the explanation was being written, the researcher moved among the participants, examined the collages and the writing products, and requested clarification of obtuse 
images or missing explanations.

At this stage the participants were asked to name the collage.

(3) Dialogue between the participant and the researcher: At the end of the writing process, the researcher should engage the participant in a dialogue regarding the work. The dialogue was recorded. It is very important for the dialogue to serve as an attempt to understand the participant's world. At this stage, the understandings, intentions, and experiences that constitute the basis of the subject's perception and understanding can be identified. The tool is not self-standing: In any event, the metaphorical collage required a verbal dialogue with the research participant so that he could explain his work and ideas to the researcher. It is impossible to rely on the collage as the only information collection tool, since the interpretation of the visual image may change from researcher to researcher. The participant's explanation of the collage permits an analysis, a processing, and an interpretation that are close to his world and relevant to his intention.

(B) Data Analysis

The data was analyzed in two stages:

\section{(1) A general description of the collage and an interpretative analysis of its components}

The analysis related to the organization of the collage (number and variety of images, text, form, size and characterization, position in the space, and direction), and an interpretative layer that related to the pictorial and verbal images in the collage (object of the metaphor, the conceptual metaphor, the process that the metaphor represents, and the researcher's comments); The researcher organized the data in a table.

(2) Results and the discussion: This part included the researcher's summary and interpretation of all the data collected from the collage.

Table 1. A general description of the collage and an interpretative analysis of its components

\begin{tabular}{|c|c|c|c|c|c|c|}
\hline \multicolumn{2}{|c|}{ Explicit level } & between the levels & \multicolumn{3}{c|}{ Implicit level } \\
\hline $\begin{array}{c}\text { general description: shape, } \\
\text { size, characterization, } \\
\text { position in the space, texts }\end{array}$ & $\begin{array}{c}\text { participant's } \\
\text { explanation }\end{array}$ & $\begin{array}{c}\text { the name of } \\
\text { the collage }\end{array}$ & $\begin{array}{c}\text { object } \\
\text { of the images }\end{array}$ & $\begin{array}{c}\text { the } \\
\text { conceptual } \\
\text { metaphor }\end{array}$ & $\begin{array}{c}\text { the process/ idea/thought } \\
\text { represented by } \\
\text { the metaphor }\end{array}$ & $\begin{array}{c}\text { interpretation } \\
\text { of the } \\
\text { researcher }\end{array}$ \\
\hline
\end{tabular}

Table 2. A general description of the collage and an interpretative analysis of its components

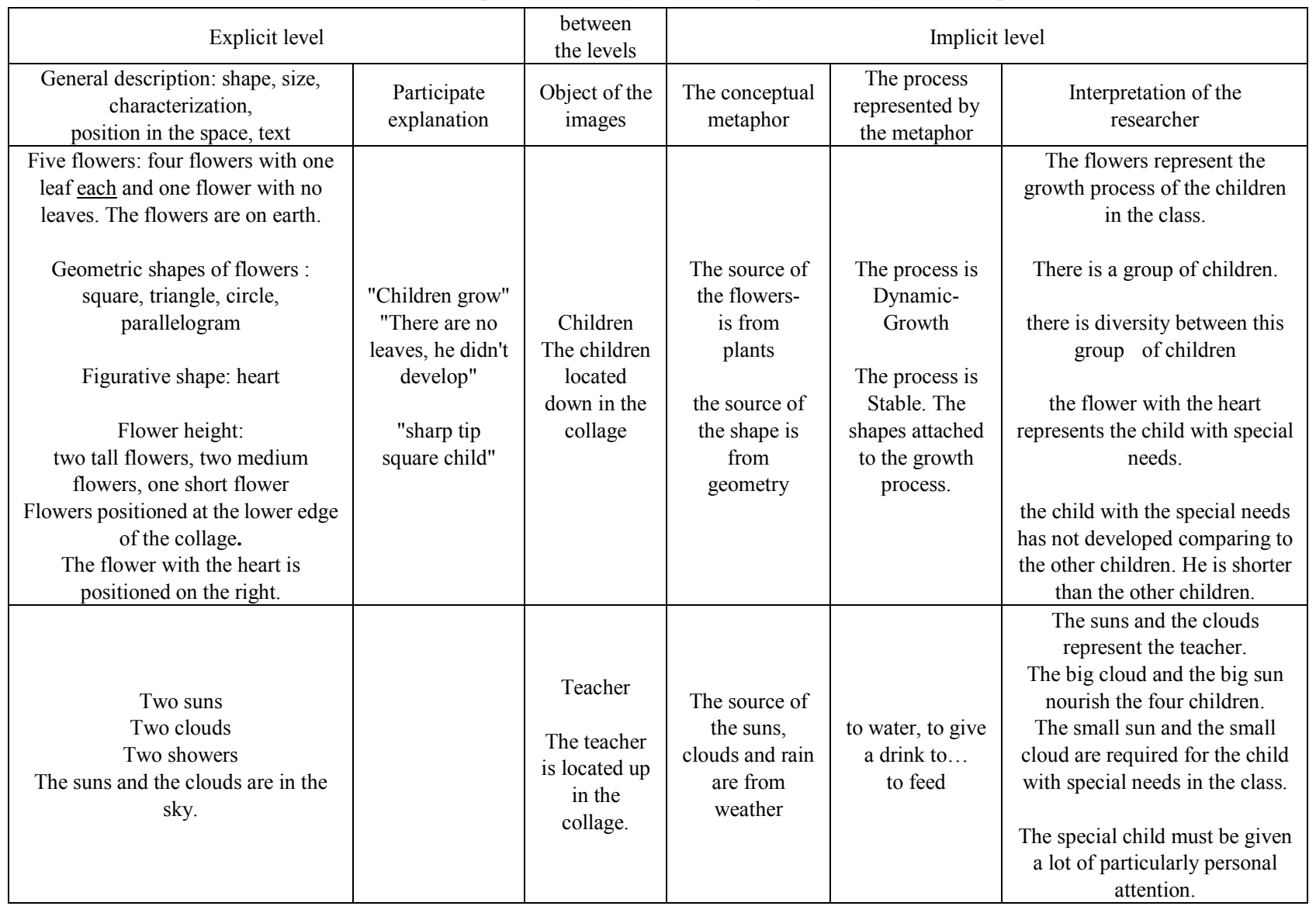




\section{Example of How to Collect and Analyze Data}

The example is presented in three stages:

\section{Stage I - Preparing the Collage}

While we were distributing the materials and providing guidance, we told the research participants: "In front of you are materials for preparing a collage. Using these materials, try to express your understanding of what a 'heterogeneous class' is, in any way you choose. You have 30 minutes." Following is one of the collages:

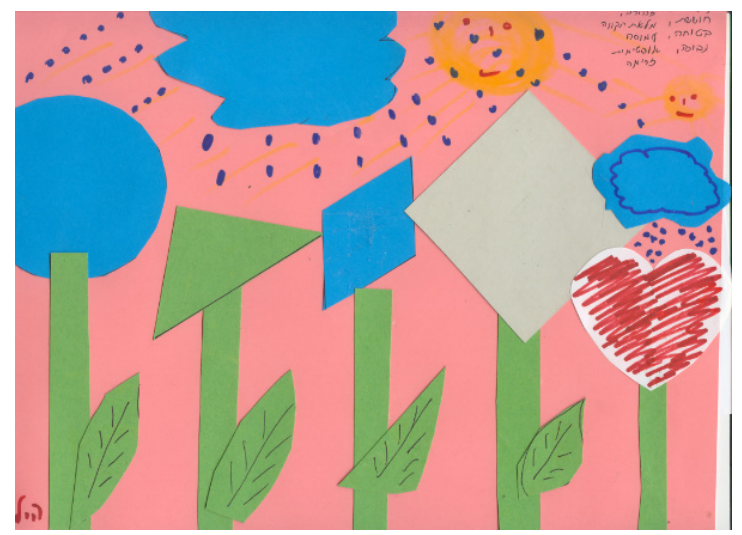

Figure 2. A collage created by one of the research participants

At the end of the collage preparation process, the participant who created Picture 1 was asked to write an explanation of the collage and attach it to the work. This is what she wrote in the explanation: "Different children receive the same resources and grow up in different ways. One is sensitive, a nerd, a square; one is cool, has his own cloud and sun, and receives more attention. The special child must be given the same resources. There are no leaves, he won't develop enough."

Throughout the dialogue the researcher asked the participant for further clarification of obtuse images or missing explanations in the collage: "Why does the child with special needs is represented by a heart shape while the others are represented by geometric shapes: circle, triangle, parallelogram, and square?" The reply was: "He needs more love."

\section{Stage II - Analysis of the Collage}

We collected all the information, and the subsequent interpretation In Table 2.

The Table was divided in 2 levels: The Explicit level that included a general description and the implicit level of the collage that included an interpretative analysis of its components.

It is clear from the table that two objects are related: the children and the teacher. The conceptual metaphors regarding the children and the teacher are different, as are the processes that each conceptual metaphor represents regarding the children and the teacher.

It is clear from the table that the research participant's words were consistent with the data analysis, and she indeed differentiated between the children and the teacher and stressed the needs of the special child, mainly in regards to the attention he merits from the teacher.

\section{Stage III - Results and Discussion}

We pooled all of the data we collected, summarized and interpreted it. As mentioned previously, the research participants were asked to use plastic materials to express their understanding of the concept "heterogeneous class". The participant who created the collage in picture 1 used various conceptual metaphors to describe the children and her role in teaching. For the description of the children, she used the central conceptual metaphor of plants (she saw the children as flowers), and the conceptual metaphor from the field of geometry (the children were marked with geometric shapes of differing sizes, each of which constituted the petals of the flower). This metaphorical description was expressed both visually and verbally. The student presented the flower on the extreme right differently from how she presented the other flowers, and made sure to use different visual materials, place in the collage and means: a red heart shape. This finding in anchored in the research literature and supports the theory that sees metaphor as conceptual cognitive phenomenon [17; 19, 20]. Or as Murray \& Rosamund [25] claimed, the metaphor is a main basic mechanism in thought that reflects a known layer and a hidden layer. Each of the original source domain picked by the participants reflects a different way of thinking.

In the process of transfer from one domain to another a mapping that includes the cases in which a term from one domain was parallel to a term from another domain was made. The mapping was manifested in the transferring of qualities and relations from content rich terms to abstract terms $[13,14]$.

We believe that this finding attests to her understanding of the diversity between the children, which seems to be expressed in a different representation of the children as flowers and is represented by means of various geometric shapes: "a triangular flower", "a square flower", "a round flower", "a parallelogram-shaped flower". In other words, a shape of some kind represents all the children, but the formal representation differs from child to child. Moreover, the diversity between the child with special needs and the rest of the children is greater, and it is reflected in a visual image of a shape that has a symbolic meaning: a heart-shaped flower. This indicates that the child with special needs resembles the rest of the children, since he too is a flower, but he is a flower that requires different care from the other children; he needs personal nurturing from the teacher, as opposed to the rest of the children, to whom the teacher relates as a group (he has his own sun and cloud). In addition, he is different from the other children because he is lacking something (he does not have leaves, he is smaller than the rest of the flowers in the garden, and he is situated at the edge).

The choice of a heart shape represents the participant's 
understanding of the uniqueness of the child with special needs. As Braden \& Hortin [3] and Dondis [9] claim, the visual language contains signs in the form of combinations of components such as dots, lines, spots, surfaces, colors, textures and images -that are culture, time, and space dependent.

Conventionally, a heart shape represents love - and in this way, she seems to stress this child's need for pronounced love and warmth on the part of the teacher. Furthermore, she chose to position him on the extreme right of the paper, and made him shorter than the other flowers. We believe that these two facts also represent the participant's understanding of the special needs child's otherness. It seems as if she focuses primarily on her role as a teacher in front of the entire class, and only afterwards does she direct her resources at the child with special needs. The image of this child at the end of the row is indicative of this understanding. The position of the child with special needs can be explained in yet another way: It is possible that the participant positioned the "heart flower" child at the side in order to allocate him a special place in the classroom. This position may indicate the special time and attention she is required to devote to him.

In the same collage, the student represents the teacher with a different conceptual metaphor. She replaced the conceptual metaphor from the plant world with one from nature: celestial bodies. This difference is not coincidental. According to Lakoff and Johnson [19], the conceptual metaphor attests to an understanding of the concept to which it is attributed; therefore, the choice of any conceptual metaphor is not coincidental. For this reason, we believe that the choice of a different conceptual metaphor is indicative of a change in thinking. The metaphors "sun" and "cloud", which are life-giving (light, heat, and rain), and the positioning of the sun and the clouds on the upper part of the page, in the "sky", evidently express the participant's understanding of the teacher's role: to give to the pupils; and the direction of the giving, according to her perception, is downward.

Furthermore, the participant doubles the sun and the cloud and draws a large, shining sun and a small shining sun, a large cloud from which rain falls and a small cloud from which rain falls. In the face of this, we believe that the student sees herself in the heterogeneous classroom as someone who is playing a double and discrete role: one concerns the whole class, and the other concerns the child with special needs. At the same time, and without a trace of a paradox, she views the child with special needs as an inseparable part of all the children in the class, and her role as personally taking care of him.

In the collage, it seems as if the picture of the sun was created with the emphasis on the face (personification): the face represents the teacher who takes care of the child with special needs (she is not laughing); while the sun represents the teacher who looks after the whole class (she is smiling). We believe that this finding attests to the difficulty of the teacher's work with the child with special needs. This interpretation can be reinforced by the written text that accompanies the collage, since on the overt level the student writes: "crowded and flowing". These metaphorical words are taken from the physical domain and attest to polarity in the description of her emotions.

In conclusion, it is possible to relate to five central components in regards to the research participant's understanding of the concept "heterogeneous class", employing the "metaphorical collage" tool: (1) the teacher perceives the class as a group (they all have a sun and one cloud); (2) the teacher relates to the child with special needs in the setting of the heterogeneous class; (3) the teacher views her role as rendering personal and individual assistance to the child with special needs (he has his own private sun and cloud); (4) the teacher stresses the particular emotional aspects that the child with special needs requires (big red heart); (5) the teacher expresses her emotions regarding the heterogeneous class. Two additional examples of analysing metaphorical collages are presented in Appendix 1 and Appendix 2.

\section{(c) Validity of the Tool}

Validity is the ability to measure, and it is based on the honest exposure of the perspectives of the people who performed the measurement. Validity requires an ongoing personal interaction, a process of breaking down and assembling, experience, a dialogue between the data and the concepts, and consultation with experts. We made sure to examine the validity of the research tool using both the qualitative and the quantitative approaches. To this end, content validity and internal validity were checked $[7 ; 15 ; 23$; $24 ; 29 ; 31 ; 32]$. The content validity of the research tool related to the units that define the tool, and was tested by two independent expert judges: an expert in the field of psychology and an expert in the field of education.

The analysis of the meanings combines the researcher's interpretation and the participant's own description of his collage, with the aim of reducing the researcher's biases.

\section{(d) Trustworthiness of the Tool}

Trustworthiness examines the extent of accuracy of each measurement. In order to achieve trustworthiness in the research, certain methods must be employed: several observers, several observations, recording information, cross-referencing information, adhering to protocols, and the complexity of the phenomenon under investigation.

The trustworthiness test of the tool was already performed in the study that examined the college students' understanding of the concepts "teaching", "learning", and "evaluation" [37].This test was performed independently by two researchers who had experience in this methodology. Each of them used the research tool separately to analyze four collages, and the results of their separate analyses were consistent with each other, manifesting a high level of trustworthiness $(89 \%)$. Following the joint discussions and the focus on the problems, the two reached a consensus. In this way, the data analysis tool according to which the collages were analyzed was built. 


\section{(e) Advantages of the Tool}

The five advantages of the tool derive from the combination of a metaphor with a collage, and they stem from the use of a metaphor in order to expose the research participant's thinking and from the method of gathering information by means of a collage. They are as follows:

(1) Simultaneous use of two languages - a visual metaphor and a verbal metaphor - as means of understanding thinking: By creating a metaphorical collage, the research participant can use two languages - visual and verbal - simultaneously. Each of the languages can enrich the other, and each of them enables other metaphors to be used.

(2) An interaction between the creator and various materials and images that is helpful in the translation of the research subject's understandings and enriches them: During the preparation of the collage, there is an interrelationship between the research participant and the concrete, external, physical stimuli. The participant undergoes inner processes as a result of the interaction with the materials. This interaction enables him to enrich his ideas, and perhaps bring them up to the surface before he examines them in depth. The material functions as a stimulus that permits the participant not only an affinity between the idea and the materials, but also a result of an affinity between the materials displayed in front of him and the idea. This step accords with Arenheim`s [1]claim that the material influences the creator, leads and directs him, and sometimes vice versa.

(3) Dialogue with the product: In this context, "dialogue" refers to the discourse that occurs between the researcher and the participant, at the initiative of either one of them. The dialogue always relates to the individual's work and takes place with the individual. Since the metaphorical collage is a visible, tangible, visual product, it enables the subject to establish a clear link with his understandings; in other words, he has time to reexamine the product and ascribe whatever meaning he likes. The collage facilitates the development of the reflective dialogue with the researcher: the latter can ask the participant about the visual images, he evokes questions in the participant, and he attempts to understand his conceptions with regard to the participant. In any event, the dialogue develops around the term or concept under investigation.

(4) Release from inhibitions: The metaphorical collage enables those who have misgivings about spoken discourse as well as those who have misgivings about drawing to use plastic materials to create, since the research participant is not required to draw his ideas, but rather is invited to express them visually, using ready-made materials. This releases any emotional inhibitions he may have regarding verbal discourse.

(5) Data collection method: The collage enables the participant to work without interference from the researcher and without guiding questions. In addition, the collage can be exhibited in the reference or any other group, and receive feedback and elucidations unexpected, perhaps - from other directions. Nevertheless, it should be remembered that the use of the metaphorical collage as a research tool is not without limitations.

\section{(f) Limitations of the Tool}

There are limitations pertaining to the nature of the tool and its interpretation:

(1) The interpretative analysis of the product: This interpretation requires skill on the part of the researchers, since they have to specialize not only in the field under investigation, but also in the domain of metaphorical thinking.

(2) The need for motor skills and working with materials: Some participants have misgivings about any use of plastic means for expressing their understandings, and they are required to overcome these misgivings.

(3) Availability of materials: It is extremely important to offer a wide range of materials for preparing the collage, and naturally, this is liable to constitute as a limitation. In addition, the entire process requires time, sometimes in excess of 30 minutes, and this may trigger impatience on the part of the participants.

\section{Conclusions}

We believe the "metaphorical collage" to be an important research tool that enables both researcher and research participant to understand the latter's worldview in regards to concepts in the field of education. The collage permits the use of expressive language in order to describe the question under investigation. The researcher has the ability to interpret the meaning of the events in which people are involved, and he is also capable of evaluating their educational significance. It is the researcher who is equipped with the requisite ability, sensitivity, and experience for conducting research by means of the "metaphorical collage". With the help of the collage, the educational situation is grasped, and its meaning interpreted.

The uniqueness of the "metaphorical collage" is expressed in three areas: (a) the method of gathering the information that facilitates expression through simultaneous verbal and pictorial images; (b) the building and processing of the data through the conceptual analysis of the visual and verbal metaphor that exposes the participant's understandings and contents that are unique to his world; (c) its nature as a communication tool that permits open, friendly, and accessible dialogue. In this way, the metaphorical collage expands and augments the possibilities of expression, enables the researcher to reach the participant's inner voice, and is instrumental in contributing further insights in educational research. 


\section{The Contribution of the Research to Teachers}

The metaphorical collage is a combination of collage work - a creation that reflects a postmodern conception and metaphor that allows visual and literal language interpretation. Metaphor and collage are two terms that represent conceptual thought that characterize the current time and mind set.

The metaphorical collage joins existing tools, such as: interview, questionnaire, and discourse - all tools that enable to expose known and hidden layers of the research participants. The collage enables using an expressive language to describe the research question. The researcher interprets the meaning of the events in which people are involved and he also has the ability to appreciate their educational meaning. It is a communication tool that enables an open, friendly accessible dialogue that broadens and intensifies the expression possibilities and allows the researcher to reach the participant's inner voice. This contributes further insights in education research.

The tool can be used by teachers on children and adolescents to expose many perceptions and understandings. It opens a window to understanding and consciousness in regards to metaphors that instruct our thoughts and actions. If we became aware of these metaphors we should be able to identify those that do not fit a certain problem. Furthermore, we will be able to build new frames of thought by creating alternative metaphors, thus finding better newer perspectives to understand and solve a problem. We can understand why philosophers explained abstract concepts using metaphors from other realms that reflect different understandings of the term in question. For example, Decart called the term mind "The Enteric Object" while Lock called it "Blank Slate"; in the $19^{\text {th }}$ century it was considered a muscle and Chomsky called it "Black Box"; Dewey considered the mind as action of independent search and organization (Doll, 1999). Each metaphor emphasizes a different aspect of the mind.

\section{Appendixes 1}

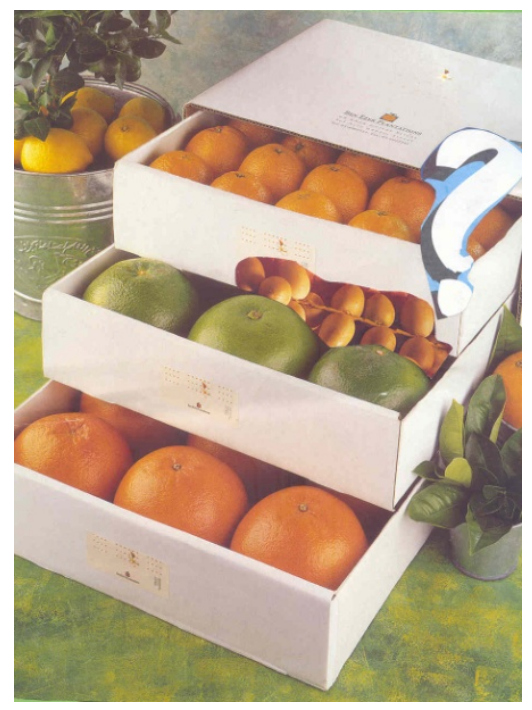

The student who participated in the study employs two different conceptual metaphors for describing the children and for describing her role in teaching: food and a receptacle. The central conceptual metaphor she utilizes for the children comes from the domain of food; she views most children as fruit of various kinds, mostly citrus fruit (pomelos, oranges, grapefruit, and lemons), which differ from one another in type and size, but are nevertheless homogeneous and classified. The exceptional fruit in the collage is the date, which is located in the center, and is found in only one group of citrus fruit, on top of the pomelos. We believe that this finding attests to the student's understanding of the diversity among the children: most of the children are similar to one another, and they are citrus fruit. The diversity among them, which is expressed in the groups of children, is not individual. That is to say, while all the children are represented as fruit from the world of food, they are organized in different groups (oranges, lemons, pomelos, and grapefruit).

The student represents the child with special needs in a different and distinct manner from the rest of the children by using a different fruit: the date. She does not use a ready-made picture from the newspaper, but rather choses to cut out a piece of fruit and paste it. Moreover, she decides to place it in the central drawer on top of the large pomelos, so that it protrudes, thus "preventing" the drawer from closing.

In the same collage, the student represents the teacher by means of a different conceptual metaphor. Instead of using a conceptual metaphor from the domain of food, she opts for one from the domain of receptacles. This change is not coincidental; rather, it attests to a change in thinking. The choice of the metaphor of a receptacle that contains all the pupils within it attests to the teacher's understanding of her role: to help the date get into the pomelo drawer. Furthermore, she chooses to cut out the collage in a similar way to a box and paste it onto the background. We believe that the teacher views her role in a heterogeneous classroom in which there are two groups - normal children and children with special needs - as assisting every group in the different way. She perceives the child with special needs in the homogeneous class that is divided up into groups as a disruptive, problematic, conspicuous, and abnormal element.

An additional characteristic of the collage is the use of graphic elements. The student elects to add a question mark to the collage. We believe that this part of the collage reflects the difficulty inherent in the teacher's work. This interpretation can be reinforced with the word "fear" that appears in the written text appended to the collage, attesting to the student's emotional state.

In summary: The research participant relates to three central components of her work in the classroom:

(1) The child with special needs stands out from the rest of the children as a result of his otherness, and he lacks the "something" that would enable him to conform to everyone else.

(2) He is a child whose disruptive behavior deprives the other children of a clear framework.

(3) The student views the class as consisting of groups, 
each one with its own uniqueness. Her role is to try to get the child with special needs to fit into the class. The interaction between her and the pupils is unclear, and she is still fearful and hesitant (question mark). As a result, she suspends the interaction for the time being.

\section{Appendixes 2}

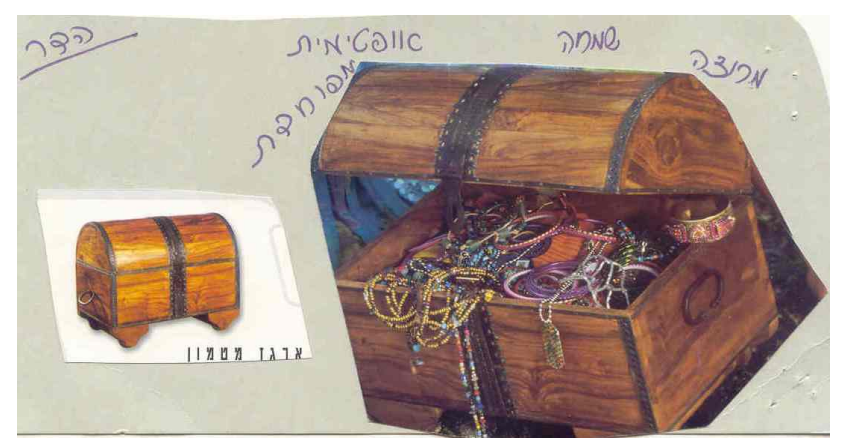

The student uses two different conceptual metaphors to describe the children and her role in teaching: the objects and the receptacle. Regarding the children, she uses a conceptual metaphor from the domain of objects; she views the children as treasure or as jewels of various types: rings, necklaces, and bracelets - some of which are golden, some colorful. It should be stressed that the child with special needs is not represented differently: all of the children are jewels.

We believe that this finding attests to the student's understanding of the diversity that exists among the children. While they are similar to one another (they are all jewels), the diversity among them is expressed in the type of jewel. The student does not stress or highlight any jewel in particular, but rather chooses jewels of which some are inside the box and others are overflowing from it. This can be interpreted, extremely cautiously, as "jewels", that is, children, who are in the framework, and as children who are outside of it.

In the same collage, the student employs a different conceptual metaphor to represent the teacher. She converts the metaphor from the domain of objects into the metaphor of a receptacle. This change is not coincidental, either; it attests to a change in thinking. The choice of the "receptacle" metaphor attests to (1) the establishment of a clear framework to which the teacher must relate, and (2) her understanding of her role. Furthermore, she chooses to cut out an additional box and paste it onto the background. We believe that the teacher views her role as looking after her pupils and being responsible for them. We could, perhaps, go further and purport that she ascribes a proprietary nature to her role as regards the pupils, namely, the treasure in her possession.

Another facet of the collage can be found in the use of verbal graphic elements. The student choses to add the words "box" and "treasure" to the closed box. This facet reinforces her feeling of responsibility and proprietorship toward her pupils. Alongside the feeling of proprietorship, she perceives them as treasure, as something that is of enormous value to its owners. The addition of the words "satisfied", "happiness", "optimism", and "afraid" attests to the fact that she relates to the class with extremely powerful mixed feelings.

In summary: The research participant relates to three central components in her classroom work:

(1) The children: All of the children are jewels, that is, valuable treasure; children are equal; all of the children are valuable, and their place is in the classroom.

(2) Her role: To look after the children, namely, the treasure that has been entrusted to her.

(3) Interaction: Her relationship with her pupils is not completely clear, and for this reason, she is fearful and afraid on the one hand and happy on the other; in other words, she still experiences mixed emotions.

\section{REFERENCES}

[1] Arenheim, R. (1966). Toward a psychology of art. Berkeley: University of California Press.

[2] Betensky, G. M. (1995). What do you see? Phenomenology of therapeutic art expression (Ch. 2, pp. 12-25). London and Bristol: Jessica Kingsley Publishers, Pennsylvania.

[3] Braden, T. A. \& Hortin, J. A. (1982). Identifying the theoretical foundation of virtual literacy. Journal of Visual Vernal Languaging, 2, 37-42.

[4] Bullough, R. V. J. (1991). Exploring personal teaching metaphors in preservice teacher education. Journal of Teacher Education, 1, 43-51.

[5] Cameron, L., \& Deignan, A. (2006). The emergence of metaphor in discourse. Applied Linguistics, 27(4), 671-690.

[6] Chesley, G. L, Gillet, D. A., \& Wagner, W. G. (2008).Verbal and nonverbal metaphor with children in counseling. Journal of Counseling \& Development, 86(4), 399-411.

[7] Cronbach, L. J. (1988). Five perspectives on validation argument. In: H. Wainer \& H. Braun (Eds.), Test validity (pp. 3-17). Hillsdale, NJ: Erlbaum.

[8] Cross, R. C., Ambrose, D., \& Cross, L. T. (2007). Metaphorical influences on thought and action: Helping the gifted escape metaphorical entrapment. Roeper Review, 29(5), $37-45$.

[9] Dole, V. (1999). Postmodern views on education. Tel Aviv: Sifriat Hapoalim. (Hebrew)Dondis, D. A. (1973). A primer of visual literacy. Cambridge Massachusetts: The MIT Press.

[10] Flood, J., Brice, H. S., \& Lapp, D. (Eds.) (1997). Handbook of research on teaching literacy through the communicative and visual arts. NY: Erlbaum.

[11] Forceville, C. (1994). Pictorial metaphor in advertisements. Metaphor and Symbolic Activity, 9(1), 1-29.

[12] Forceville, C. (1995). This version sent to Poetics on 27 October 1994 IBM is a tuning fork: Degrees of freedom in the interpretation of pictorial metaphors. Poetics, 23, 189-218. 
[13] Gentner, D. (1983). Structure-Mapping: A theoretical framework for analogy, Cognitive Science, 7, 155-170. Retrieved January 2010 from: http://www3.interscience.wiley.c om.ezproxy.levinsky.ac.il/user/accessdenied?ID $=122517033 \&$ Act $=2138 \&$ Code $=4719 \&$ Page $=/$ cgi-bin $/$ fulltext $/ 122517033 /$ PD FSTART

[14] Gentner, D., \& Markman, A. B. (1997). Structure mapping in analogy and similarity. American Psychologist. 52(1), 45-56. Retrieved January 2010 from: http://psycnet.apa.org.ezproxy.le vinsky.ac.il/journals/amp/52/1/45.pdf

[15] Goetz, J. P., \& Le Compte, M. D. (1984). Ethnography and qualitative design in educational research. Orlando, FL: Academic Press.

[16] Green, D., \& Kupferberg, I. (2001). Detailed and succinct self-portraits of addicts in broadcast stories. Discourse Studies, 2(3), 305-322.

[17] Lakoff, G. (1987). Woman, fire and dangerous things; what categories reveal about the mind. Chicago: University of Chicago Press.

[18] Lakoff, G. (1991). Metaphor and war: The metaphor system used to justify war in the Gulf. Peace Research, 23, 25-32.

[19] Lakoff, G., \& Johnson, M. L. (1980). Metaphors we live by. Chicago: University of Chicago Press.

[20] Lakoff, G., \& Johnson, M. L. (1999). Philosophy in the flesh: The embodied mind and its challenge to western thought. New York: Basic Books.

[21] Marshall, H. (1990). Metaphor as an instructional tool in encouraging student teacher reflection. Theory into Practice, $29,128-132$.

[22] Merleau-Ponty, M. (2004). The eye and the spirit. Tel Aviv: Resling. (Hebrew).

[23] Messick, S. (1989). Validity. In: R. L. Linn (Ed.), Educational Measurement ( $3^{\text {rd }}$ ed., pp. 13-103). New York: Macmillan.

[24] Moss, P. A. (1994). Can there be validity without reliability? Educational Researcher, 23(2), 5-12.

[25] Murray, K., \& Rosamund, M. (2006). Introducing Metaphor. London: Routledge, Taylor \& Francis Group.

[26] Rowland, K. F. (1964). Eleventh Impression. London: Ginn.
[27] Russo-Zimet, G. (2013). Young children's perception of the concept of noise as Conveyed in Visual Representations. Research \& early childhood education, 2, 20-51. http://sites.levinsky.ac.il/wordpress/kindergarten/.(Hebrew).

[28] Russo-Zimet, G., \& Segel, S. (2014). The Concept of Happiness as Conveyed in Visual Representations: Analysis of the Work of Early Childhood Educators. Journal of Education and Training Studies, 2(4), 97-107

[29] Sabar, N. B. (2001). Traditions and trends in qualitative research. Lod: Dvir (Hebrew).

[30] Schön, D. A. (1979). Generative metaphor: A perspective on problem-setting in social policy. In: A. Ortony (Ed.), Metaphor and thought (pp. 137-163). Cambridge: Cambridge University Press.

[31] Scriven, M. (1972). Objectivity and subjectivity in educational research. In: L. G. Thomas (Ed.), Philosophical redirection of educational research. (pp.94-142). Chicago: University of Chicago Press.

[32] Shepard, L. A. (1993). Evaluating test validity. Review of Research in Education, 19, 405-450.

[33] Snyder, C. (2012). A case study of a case study: Analysis of robust qualitative research methodology. The Qualitative Report, 17, 1-21.

[34] Stake, R.E. (1994). Case Studies. In N.K. Denzin \& Y. S. Lincoln (Eds.), Handbook of qualitative research (pp. 236-247).Thousand Oaks: Sage.

[35] Stake, R.E. (2005). Multiple case study analysis. New York: Guilford Press.

[36] Stake, R.E. (2008).Qualitative case studies. In N.K. Denzin \& Y. S. Lincoln (Eds.) Strategies of qualitative inquiry (pp.119-149). Thousand Oaks, CA: Sage.

[37] Zimet, G., \& Dan, Y. (2006). Metaphors as a tool for exposing student teachers' conception of the concepts "teaching", "learning" and "evaluation". Shvilei Mekhkar, 13, 72-81. (Hebrew).

[38] Zimet, G., \& Dan, Y., \& Gilat, I. (2009). Metaphorical Collage as a Research Tool in the Field of Education. Dapim, 48, 163-201. (Hebrew).

[39] Yin, R.K.(2012). Applications of case study research (3d. Ed.) California: Sage. 